\title{
A new scaled fuzzy method using PSO segmentation (SePSO) applied for two area power system
}

\author{
Balasim M. Hussein \\ Department of Power and Electrical Machines, College of Engineering, University Of Diyala Diyala, Iraq
}

\begin{tabular}{l} 
Article Info \\
\hline Article history: \\
Received Apr 27, 2018 \\
Revised Sep 13, 2018 \\
Accepted Oct 4, 2018 \\
\hline
\end{tabular}

\section{Keywords:}

Control

Frequency

Scald-fuzzy

Segmentation

Two area

\begin{abstract}
The balance of the power supply and demand (frequency control) is one of the most ancient approaches for the power systems, which is considered as a highly complex system. The power systems frequency response is a perfect indicator of the resilience to the multi-disturbances. In this work, the fuzzy logichas been scaledusing PSO segmentation (SePSO) and suggested to get high performance of frequency stability. PSO has participated into multisegments for calculating the scald-fuzzy membership with basic rules. Two identical interconnectedpower areas wereselected to exam the new scaled fuzzy method. The time response of the results has undertaken the effectiveness of the controller reactionusing the MATLAB Simulink. The work feed back proved that the proposed SePSO optimization for the controlhas significantly faster with low undershot concerningthe classical controllers in differenttime schedules and disturbance values.
\end{abstract}

Copyright $\odot 2019$ Institute of Advanced Engineering and Science. All rights reserved.

\section{Corresponding Author:}

Balasim M.Hussein,

Electrical Engineering Department,

College of Engineering,

University of Diyala,

Diyala, Iraq.

Email: balasim@inbox.ru

\section{INTRODUCTION}

The objective of generating a good quality of an electrical power system is to supply energy to consumers at nominal system frequency and voltage [1]. The balancing of power generation with the load demand is a real challenge in the highly complex controlled system [2]. Normally, the steady-state frequency is changing by the random variation of the customer's energy demand, and LFC is the controller which responsible for reset the normal condition [2].

The LFC performance is directly affecting by the feedback controller design to maintain the power transferred between the two areas at its' expected values [3]. The area control error (ACE) is most important challenge in the LFC loop which is representing as the control output[3].

The classical controllers have been used in different power system operation and control topics due to its simplicity. But, the main drawback of classical controller is tuning its parameters and it is design for narrow conditions [2], [3].

To counteract the bad circumstances of classical frequency controllers; many intelligent control methods have been put forward and studied towards developing the stability [3], [4].

Normally the fuzzy controllers have not been able to diminish the darkness beyond of classical controllers, therewith the cases which are examined with the intelligent methodology are undoubtedly negligible with respect to the uncompensated problems [1]. Ones of the most realistic conditions to geta promised results in any fuzzy controller are the obtaining and optimizing the fuzzy rules and its' memberships [5]. 
PSO control fuzzy gain at each area after sudden update of the active power using a new algorithm suggested by A. Jaber et al., [6]. Other works, involved the use of Genetic Algorithm or Ant Colony Optimization to scald the fuzzy for driving the frequency control in power systems [7]-[9].

However, even though PSO or Ga strategies to scale the fuzzy is performing well in some cases, they may fail to ensure that the frequency response [10]-[12].

In this paper, Se-PSO was used to get the optimal gain to scale the fuzzy PID controller. This controller has appliedto two symmetrical areas which were simulated using MATLAB. The range initial values o of the Fuzzy controller gains have been divided into a different number of segments. The simulation results have demonstrated the feasibility of the ensemble in the suggested method via ITAE properties estimation approach with respect to PID and PSO-scaled fuzzy.

\section{MODEL OF INTERCONNECTED POWER SYSTEM AREAS}

The two main reasons for Automatic Generation Control (AVC) to neglect Automatic Voltage Regulator the AVR loop In interconnected power system are:-

a) The voltage remains fairly constant during small changes in the system's load, while the deviation in frequency.

b) The AVC is faster than the prime mover reaction.

So the model is consist of four parts of simulation (Governor Turbine Model, Tie Line Model, and Control Area Modeling)

The parameters of the separatedarea of a power systemcan represent inthe block diagram as follows [13]-[19]. Single area power system is shown in Figure 1.

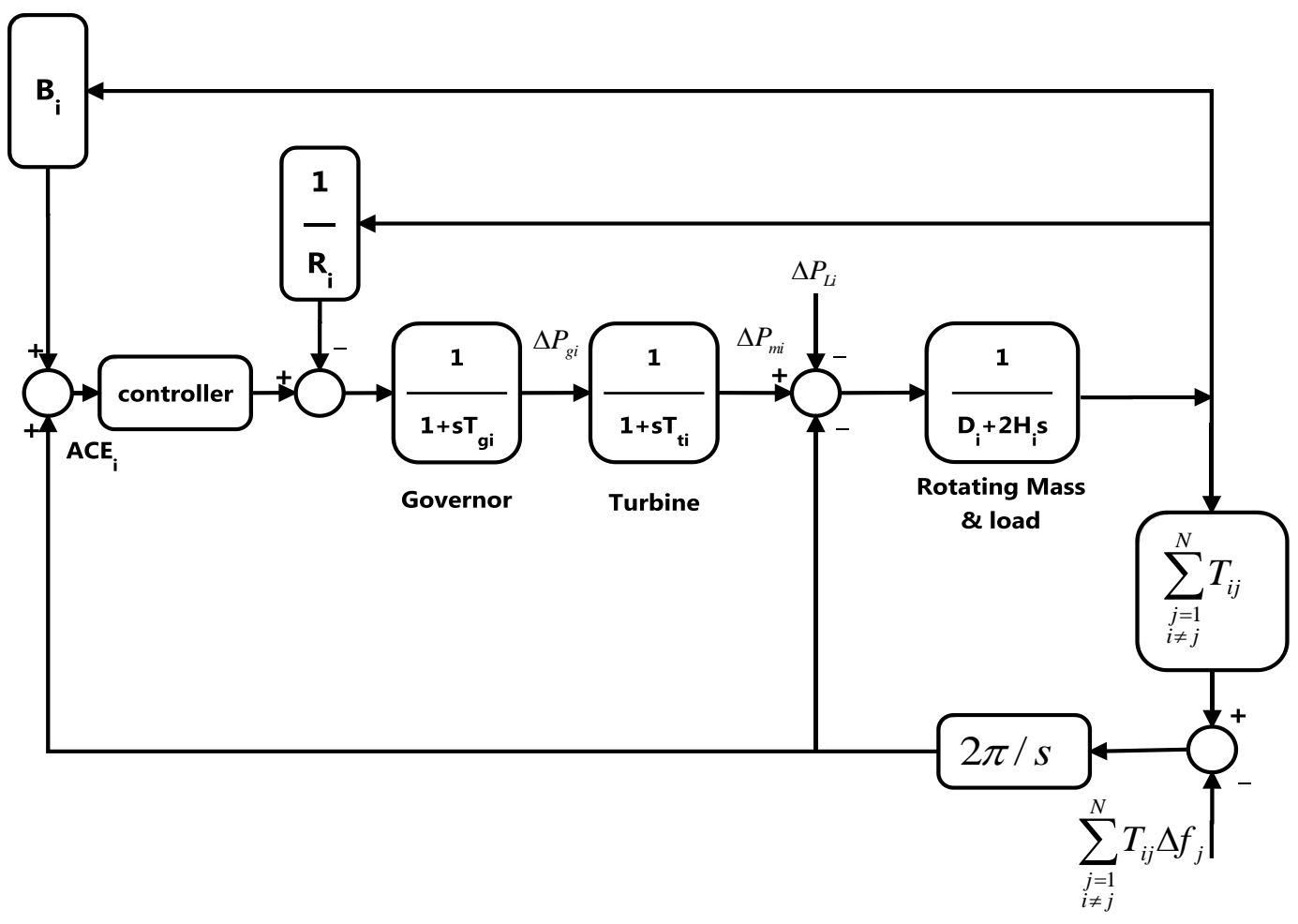

Figure 1. Single area power system

\section{PSO MATHEMATICAL MODEL} method [20].

In 1995, PSO algorithm was introduced by Eberhart and Kennedy as a novel heuristic

The PSO index of the best particle in the population is representingby the symbol g. At each time step $\mathrm{t}$ in the simulation the velocity of the $\mathrm{i}^{\text {th }}$ particle represented as $v_{i}=\left(v_{i 1}, v_{i 2}, \ldots, v_{i d}\right)$, is adjusted along each axis $\mathrm{j}$ the equation. 


$$
v_{i}(t+1)=\omega v_{i}(t)+c_{1} r_{1}\left(p_{i}(t)-X_{i}(t)\right)+c_{2} r_{2}\left(G_{i}(t)-X_{i}(t)\right)
$$

Where $c_{l}, c_{2}$ are acceleration coefficients, $p_{i}$ and $\mathrm{G}_{\mathrm{i}}$ the local and global optimum point after each iteration respectively, and $\omega$ is weight of inertia.

$\mathrm{p}_{\mathrm{i}}$ and $\mathrm{G}_{\mathrm{i}}$ are cognitive and social acceleration coefficient. Also, the particle's velocity range is constant and updating for each iteration as :

$$
v_{i j}=\left[-V_{\max }, V_{\max }\right]
$$

The new position of a particle is calculated according to the equation shown:

$$
X_{i}(t+1)=X_{i}(t)+v_{i}(t+1)
$$

Moreover, personal new position of the particle is updated using

$$
p_{i}(t+1)=\left\{\begin{array}{c}
p_{i} t f\left(x_{i}(t+1)\right)<f\left(p_{i}(t)\right) \\
x_{i}(t+1) f\left(x_{i}(t+1)\right)<f\left(p_{i}(t)\right)
\end{array}\right.
$$

While the global best index is defined as:

$$
\left.g=\arg \min f\left(p_{i} ; t+1\right)\right), 1 \leq i \leq N
$$

\section{SePSO METHOD}

The requirement to develop a new technique to increase the accuracy of PSO was became one of the main topics in optimization science. The case of existing more than an optimal point which is explained in 2.4 , is a big problem in PSO.

The divided of the searching particles into searching groups is the aim of the proposed method. Each segment is a PSO algorithm to evaluate the global point as shown in Figure 2. The optimal initial range is always given a faster convergence to achieve the optimal global point [20].

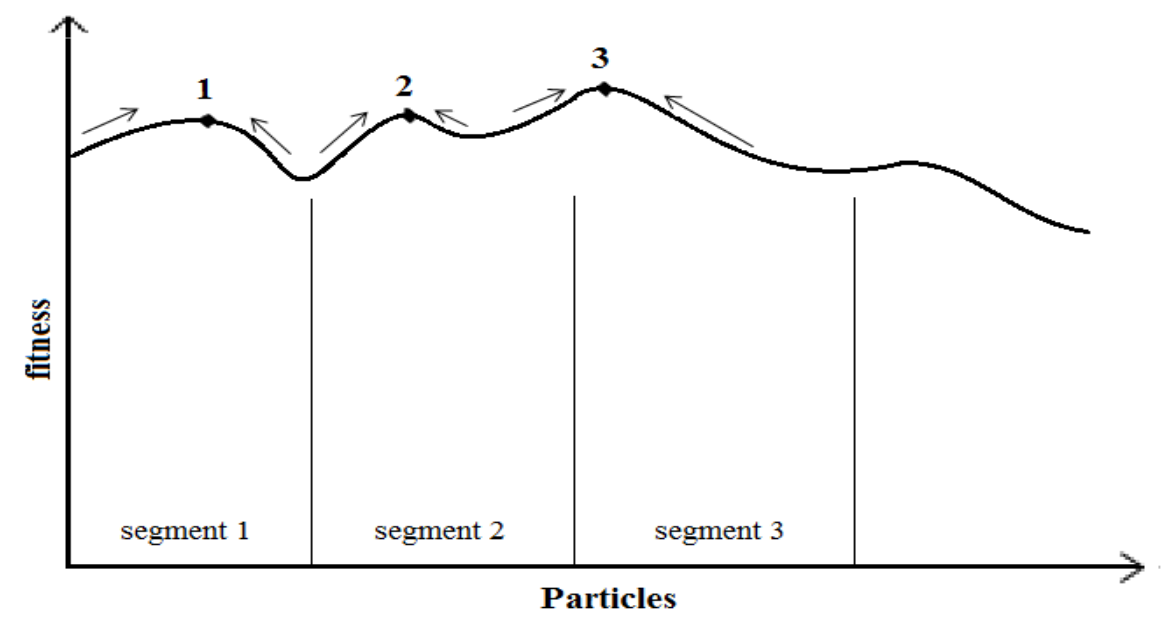

Figure 2. Optimal local and global points

In Figure 2, points 1,2 and 3can be assumed as a segment optimal local points,butthe global optimal point is3. A modification of PSO equations with additional equation have been done to get the optimal segment and point as shown [21];

$$
\text { Segment length }=\text { initial limits } / \text { no. of Segments }
$$

$$
\mathrm{v}_{\mathrm{ij}}(\mathrm{t}+1)=\omega \mathrm{v}_{\mathrm{ij}}(\mathrm{t})+\mathrm{c}_{1} \mathrm{r}_{1}\left(\mathrm{p}_{\mathrm{i}}(\mathrm{t})-\mathrm{X}_{\mathrm{ij}}(\mathrm{t})\right)+\mathrm{c}_{2} \mathrm{r}_{2}\left(\mathrm{G}(\mathrm{t})-\mathrm{X}_{\mathrm{ij}}(\mathrm{t})\right)
$$

A new scaled fuzzy method using PSO segmentation (SePSO) applied for two... (Balasim M. Hussein) 
$X_{i j}(t+1)=X_{i j}(t)+v_{i j}(t+1)$

Hence;

$$
\text { optimal segment }=\text { optimal } X_{\mathrm{ij}} \mp \text { segment } \frac{\text { lenght }}{2}
$$

Where, $j$ is the totalparameter segment number. Also the flowchart of the SePSO is shown in Figure 3.
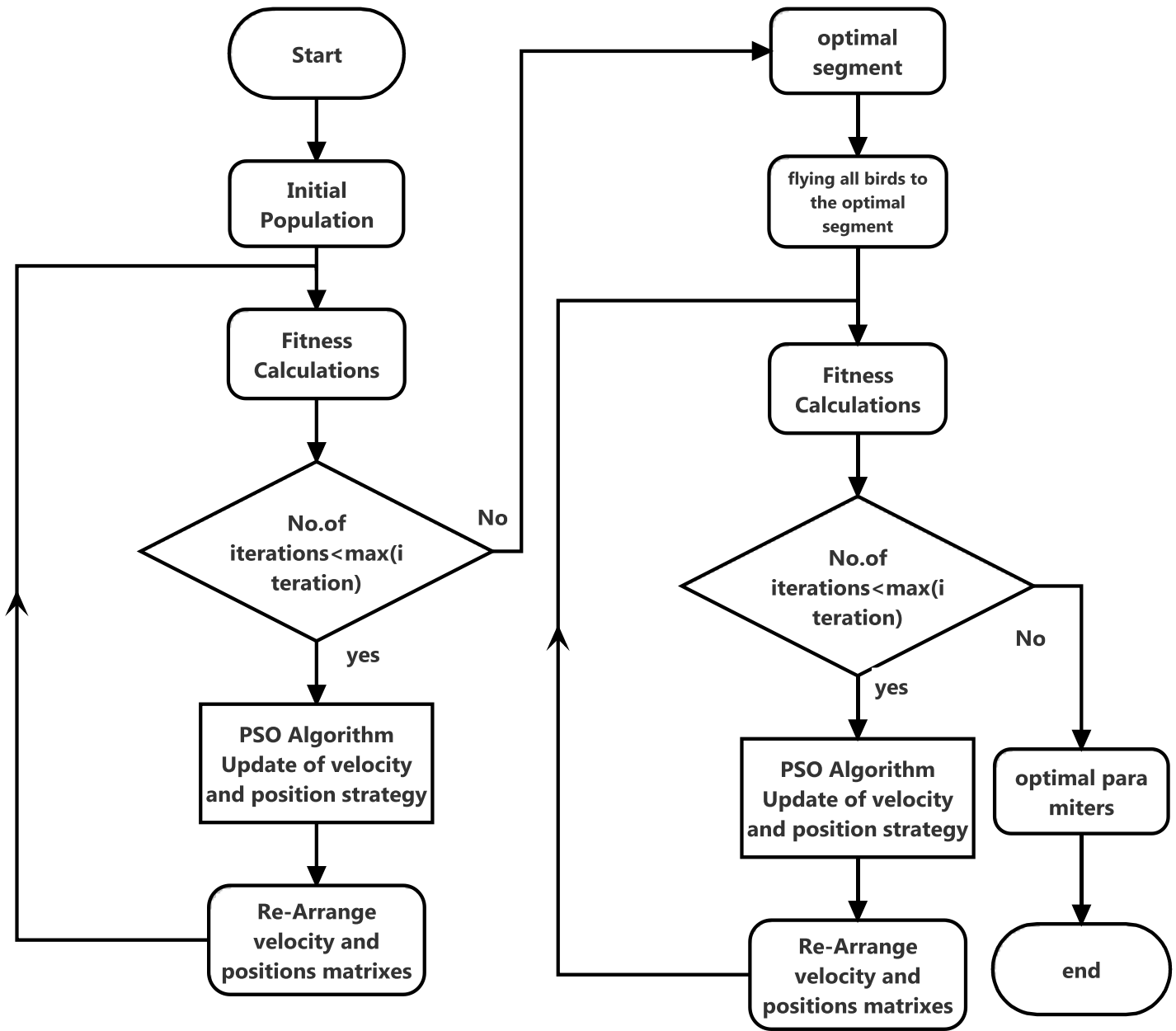

Figure 3. SePSO optimization

\section{SCALED FUZZY CONTROLLER}

The expert in classical Fuzzy methods is the adjusted way to calculate the boundary of the fuzzy membership functions, which is not sure to guarantee the systems' performance [2]. On the other hand, using of intelligent search optimization methods to select the boundaries of the memberships are limited upon the designed operation conditions.

The Scaled Fuzzy controller can increase the control operation conditions. This controller is depending on adapting the error and the change of error (the input of the fuzzy controller) according to the fuzzy membership instead of changing the memberships according to the operation condition.

For example, we supposed that the boundaries of the input to the fuzzy controller are from 100 to -100 , and the selected memberships are from 1 to -1 . In this case to adapt the input with the fuzzy system we can multiply the input by a gain of $1 / 100$ without need to change in fuzzy membership figures. This gain is called the scaled fuzzy parameter. Figure 4 is show the overall scaled parameter control. 


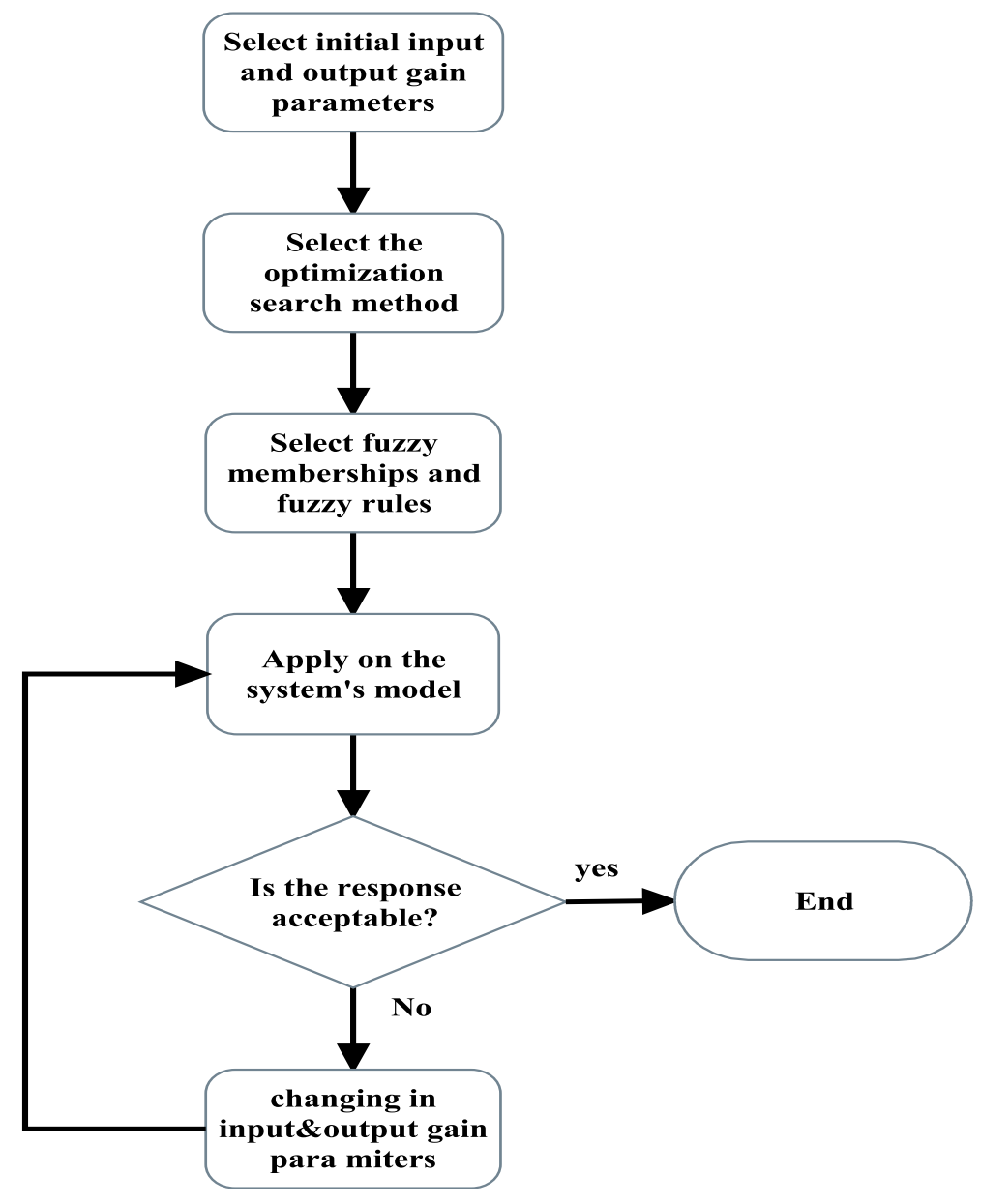

Figure 4. Scaled fuzzy controller

Was proposed to control the frequency by Broujeni [14]. However, the using of GA may effect by the initial values which caused to divergence and convergence of the optimum point.

\section{THE PROPOSED METHOD}

To overcome the slow response of using the GA and PSO in scaled fuzzy PI controller, A combination between SePSO and fuzzy PI controller the boundaries to Synthesis the membership functions (scaled fuzzy gains). These gains represented by three parameters Gout, Gin1, and Gin2, which are shown in Figure 5 [2], [14]. The rule of the fuzzy has been suggested as in Table1 according to the inputs and the output membership function which are shown in Figure 6. The flow chart of SePSO algorithm to scaled the fuzzy PI parameters as optimal response is shown in Figure 7.

Table 1. Scaled Fuzzy Rules

\begin{tabular}{llllll}
\hline $\mathrm{e} / \Delta \mathrm{e}$ & $\mathrm{PP}$ & $\mathrm{SP}$ & $\mathrm{ZE}$ & $\mathrm{SN}$ & $\mathrm{NN}$ \\
\hline $\mathrm{PP}$ & $\mathrm{PP}$ & $\mathrm{SP}$ & $\mathrm{SP}$ & $\mathrm{ZE}$ & $\mathrm{ZE}$ \\
$\mathrm{SP}$ & $\mathrm{SP}$ & $\mathrm{SP}$ & $\mathrm{ZE}$ & $\mathrm{ZE}$ & $\mathrm{NS}$ \\
$\mathrm{ZE}$ & $\mathrm{SP}$ & $\mathrm{ZE}$ & $\mathrm{ZE}$ & $\mathrm{NS}$ & $\mathrm{NS}$ \\
$\mathrm{SN}$ & $\mathrm{ZE}$ & $\mathrm{ZE}$ & $\mathrm{NS}$ & $\mathrm{NS}$ & $\mathrm{NN}$ \\
$\mathrm{NN}$ & ZE & NS & NS & NN & NN \\
\hline
\end{tabular}

Where: PP: medium positive, SP: small positive,SN: small negative, ZE: zero and NN: medium negative. 
The rules in the fuzzy controller which are used in this works can be listed in Table 1. Also a basic membership function sets of identical triangles was used for the input and the output of fuzzy as shown in Figure 6. In this controller, MOMdefuzzification method has been performed in this work.

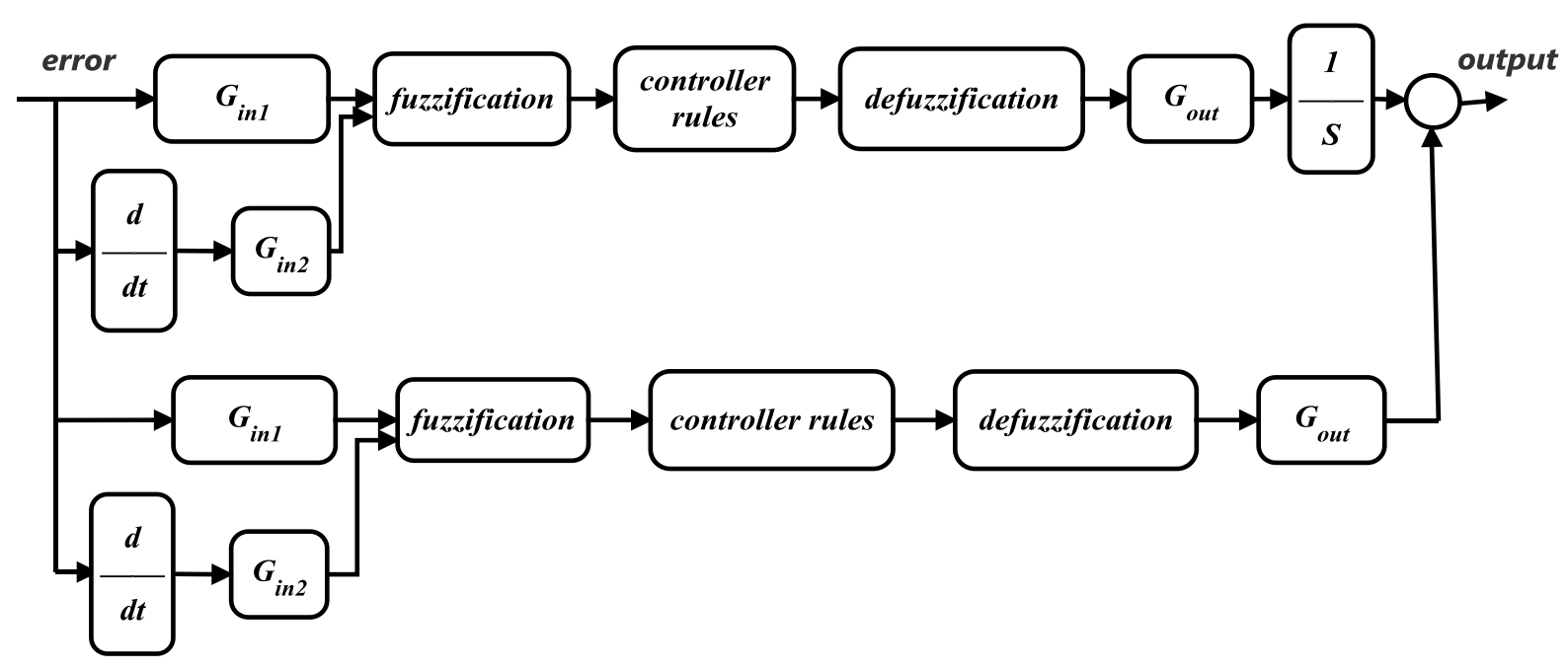

Figure 5. Scaled Fuzzy PI controller

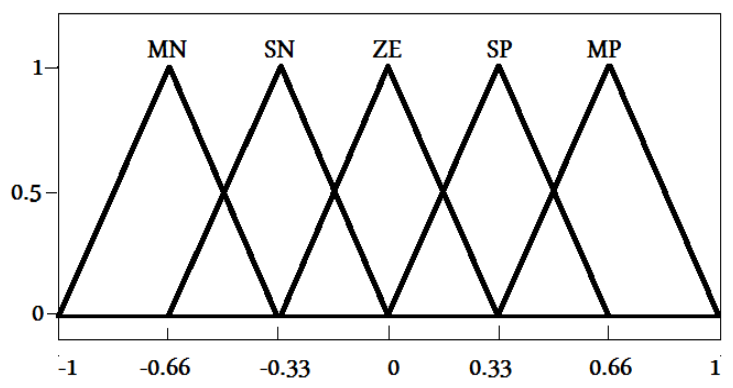

Figure 6. Input \& output Membership

On the other hand, the change and developing of basic PSO have reduced the weak points of optimal solution of many problems [21], [22]. Among the partial swarmimprovement, the algorithms searching has been dividedinto groups each one was named segment, and the method was named PSO segmentation [20].

In this paper, Se-PSO was used to calculate the optimal gain to scale the fuzzy PID controller. The fuzzy controlhas appliedto two symmetrical areas which were simulated using MATLAB. Each of $\mathrm{Kp}, \mathrm{Kd}$, and Kiinitial values ranges have divided into a different number of segments. The simulation results have demonstrated the feasibility of the ensemble in the suggested method via ITAE properties estimation approach. 


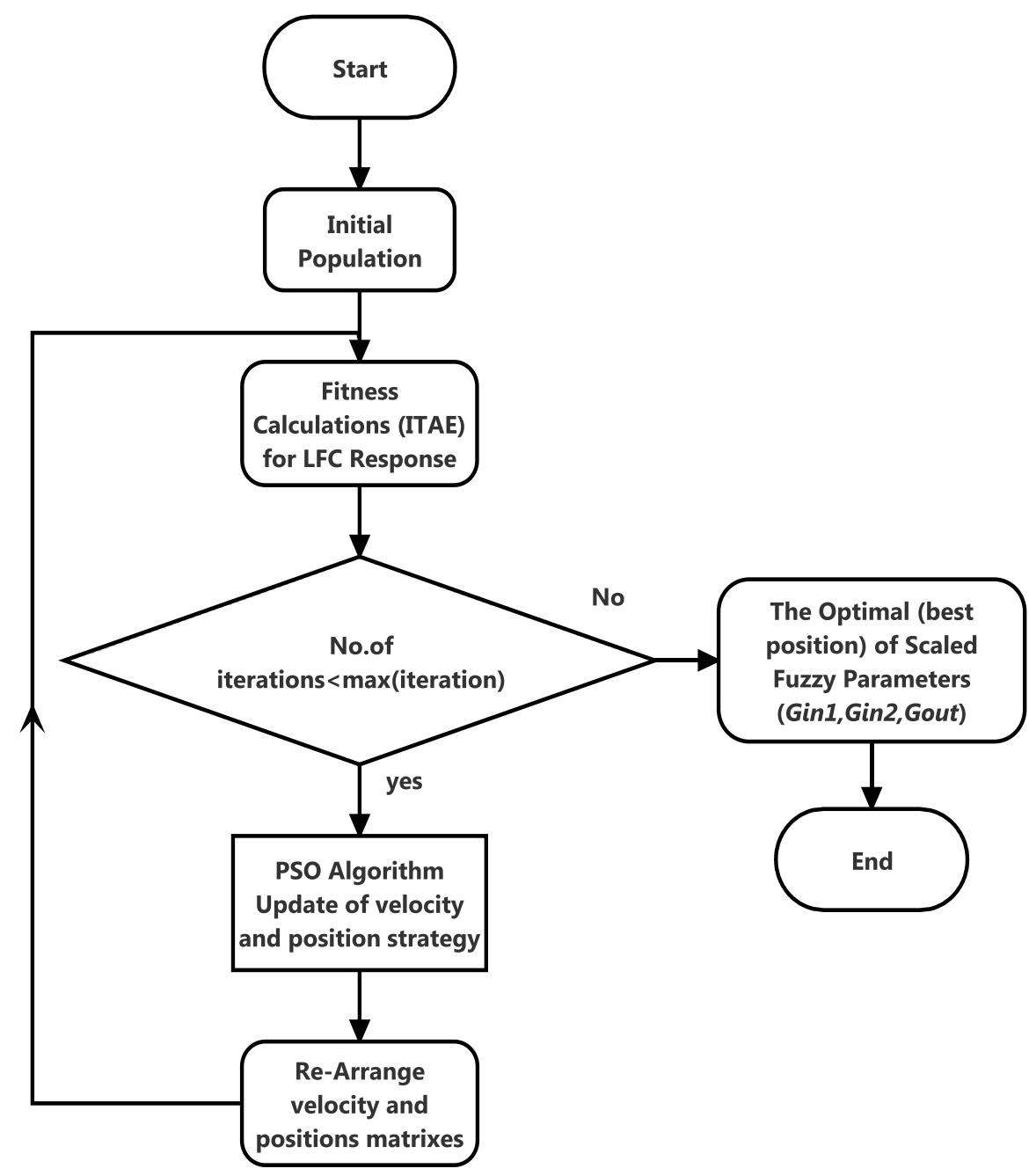

Figure 7. Scaled fuzzy parameter using SePSO

\section{SIMULATION RESULTS}

The simulation parameters which is used in this paper are given in Table 2. The first Simulation disturbance in the power system was set to $30 \mathrm{~s}$ and the deference moments of load change. Both of the two areas were sets to $10 \%$ of suddenly deviation in the power but with 0 and 2 second respectively and Figure 8 shows the time response of the frequency.

Secondly; four values of disturbance in the second area with same time schedule and disturbance of area one were selected to validate the system, one of their shown in Figure 9. A nother three disturbance cases can be noted in Table 3, which are showing the time responses of the system. The higher advantage of the proposed method is $0.0121 \mathrm{pu}$ with $20 \%$ disturbance.

Table 2. System Parameters

\begin{tabular}{ccccc}
\hline $\mathrm{R}$ & $\mathrm{Ts}$ & $\mathrm{Tt}$ & $\mathrm{Kp}$ & $\mathrm{Tp}$ \\
\hline 2.4 & 0.08 & 0.03 & 120 & 20 \\
\hline
\end{tabular}

Table 3. The Properties of Changing Power in Area Two

\begin{tabular}{clccccc}
\hline Area2 Changing & \multicolumn{2}{c}{ PID } & \multicolumn{2}{c}{ PSO-Fuzzy } & \multicolumn{2}{c}{ SePSO-Fuzzy } \\
& U-Sh & Settling time & U-Sh & Settling time & U-Sh & Settling time \\
\hline $10 \%$ & 0.0754 & $>30$ & 0.0681 & 23.231 & 0.0649 & 21.414 \\
$20 \%$ & 0.0913 & $>30$ & 0.0831 & 24.431 & 0.0792 & 22.944 \\
$25 \%$ & 0.0908 & $>30$ & 0.0994 & 25.112 & 0.0866 & 23.216 \\
\hline
\end{tabular}

A new scaled fuzzy method using PSO segmentation (SePSO) applied for two... (Balasim M. Hussein) 
Where:- U-Sh is undershot

Also multi-disturbances of both areas with same time schedule was applied to exam the new scaled method, one of their shown in Figure 10. A nother cases seen in Tableb4. The dark words of the classical controller can be clearly notes in the Table 4 .

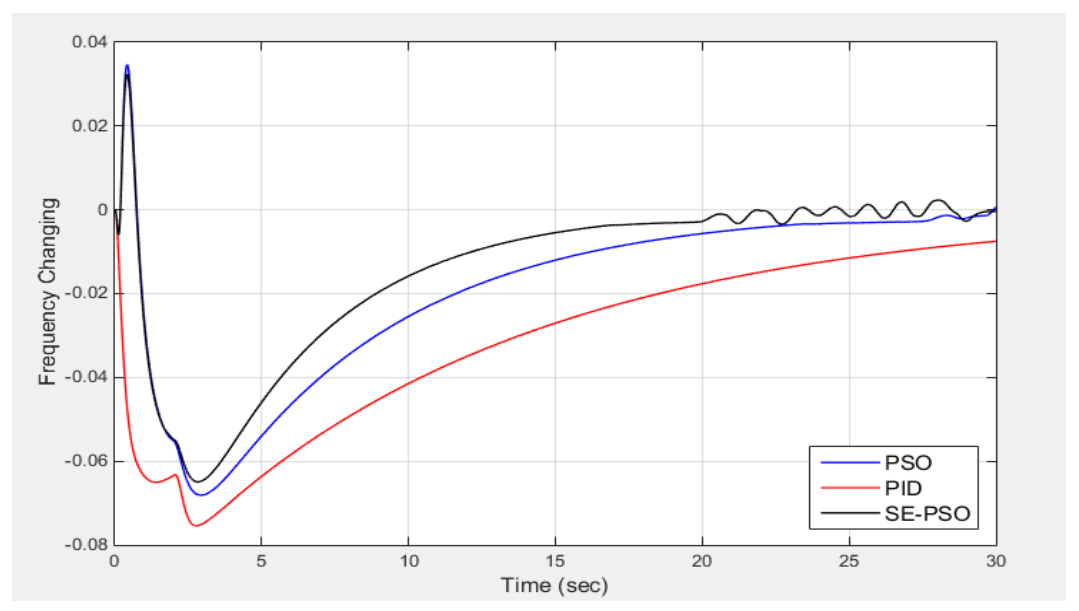

Figure 8 . Frequency changing of case 1

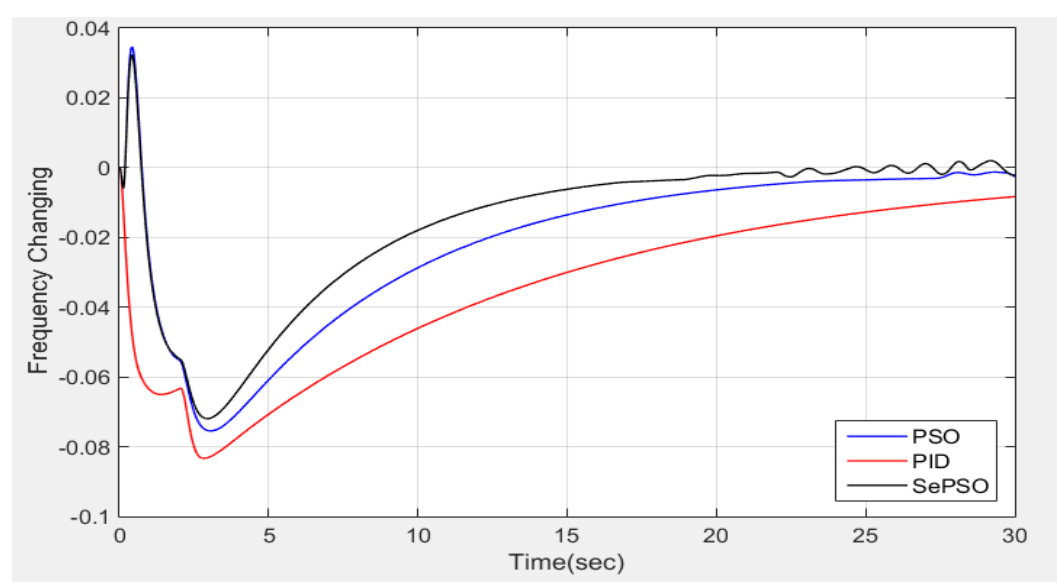

Figure 9. Frequency changing $10 \%$ area $1,15 \%$ area2

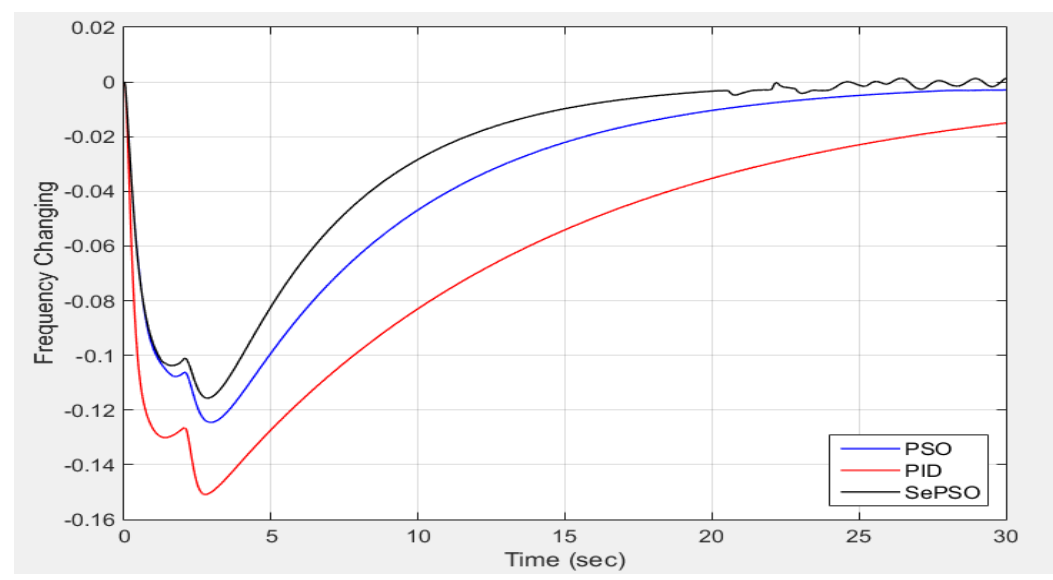

Figure 10. Frequency changing 20\% area1, 20\% area2 
Table 4. The Properties of Changing Power in Both Areas

\begin{tabular}{cccc}
\hline Both Area & PID & PSO-Fuzzy & SePSO-Fuzzy \\
Changing & U-Sh & U-Sh & U-Sh \\
\hline $10 \%$ & 0.0754 & 0.0681 & 0.0649 \\
$30 \%$ & 0.1870 & 0.2263 & 0.1738 \\
$40 \%$ & 0.3017 & 0.2495 & 0.2317 \\
\hline
\end{tabular}

Lastly the change was in time schedule of the disturbances; the disturbance of the first area is always zero sec, but the second disturbance changed from 4 to 8 second, for 4 sec time disturbance shown in Figure 11. Another three cases are supposed in time schedule and the results can be shown in Table 5 .

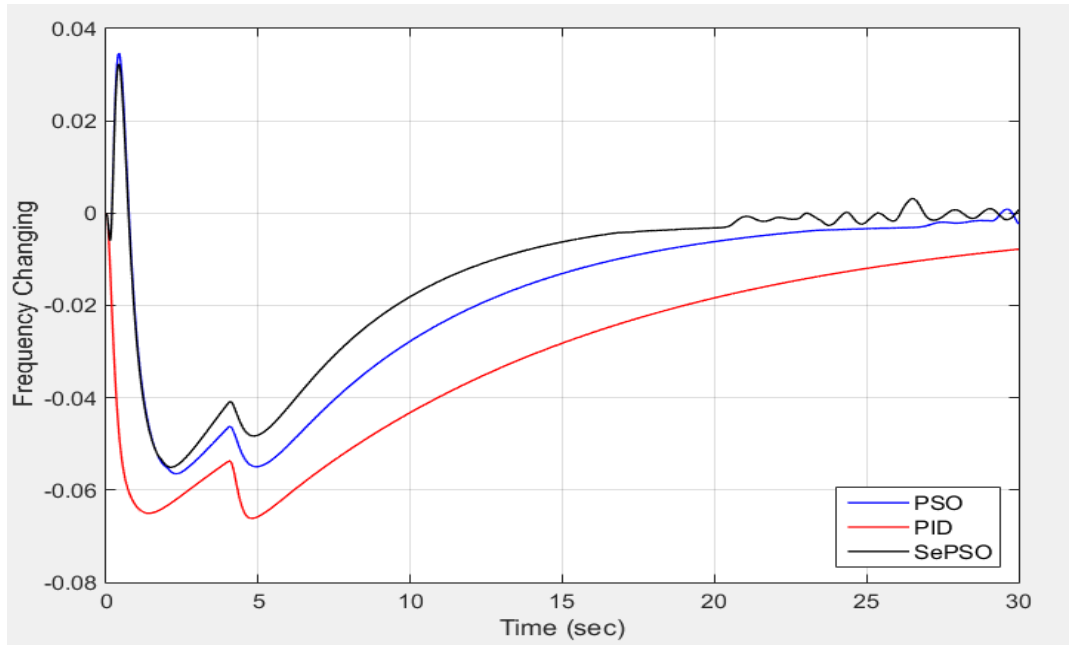

Figure 11. Frequency changing with $4 \mathrm{sec}$ schedule time of area2

Table 5. The Properties of Changing Time Schedule

\begin{tabular}{clll}
\hline Disturbance & PID & PSO-Fuzzy & $\begin{array}{c}\text { SePSO-Fuzzy } \\
\text { U-Sh }\end{array}$ \\
\hline Timeof Area2 & U-Sh & 0.0681 & 0.0649 \\
6 & 0.0754 & 0.0565 & 0.0551 \\
8 & 0.0650 & 0.0565 & 0.0551 \\
\hline
\end{tabular}

It can be notes from figures and tables that the secondary control action is effecting on the responses.

So the decreasing in settling time of the proposed controller is only a few seconds specially compared with PSO-Fuzzy controller.

\section{CONCLUSION}

One of the main challenges in automatic operation multi-area power systems is the Load Frequency Control (LFC). LFC is responsible on scheduled power calibration between the multi-areas at any disturbances. Such as; the connecting or disconnecting generating unit or suddenly large increasing demind. In this work, the proposed scaled fuzzy controller examines on two areas power system using PSO, SePSO also PID. These rules are obtained based on Matlab simulation of frequency response, error signal and its time changing. The simulation results prove that the suggested controller has obtained a high speed of response and less undershoots withrespect to the controlusing PID, and PSOfuzzy controller. 


\section{REFERENCES}

[1] S. A. Azeer, et al., "Intelligent Controllers for Load Frequency Control of Two-Area Power System," Science Direct, vol. 50, no. 2, 2017, pp. 301-306.

[2] Aqeel S. Jaber, et al., "Advance Two-Area Load Frequency Control using Particle Swarm Optimization Scaled Fuzzy Logic,” Adv. Mater. Res., vol. 622-623, 2013, pp. 80-85, 2013.

[3] M. Najeeb, et al., "An Optimal LFC in Two-Area Power Systems Using a Meta-heuristic Optimization Algorithm," International Journal of Electrical and Computer Engineering, vol. 7, no. 6, pp. 3217- 3225, 2017.

[4] T.P. Dao, et al., "Novel Hybrid Load-Frequency Controller Applying Artificial Intelligence Techniques Integrated with Superconducting Magnetic Energy Storage Devices for an Interconnected Electric Power Grid," King Fahd University of Petroleum \& Minerals Journal 2015.

[5] T. Wen, "Load Frequency Control: Problems and Solutions," Control Conf. (CCC), 30thChinese, 2011, pp. 6281-6286.

[6] Aqeel S. Jaber, et al., "A new Improvemrnt of Conventional PI/PD contrllers fot load frequency control with scaled fuzzy controller," International Journal of Engineering and Applied Sciences, vol. 2, no. 4, 2015, pp. 69-74.

[7] Hassan Farhan Rashag, et al., "Modified Direct Torque Control using Algorithm Control of Stator Flux Estimation and Space Vector Modulation Based on Fuzzy Logic Control for Achieving High Performance from Induction Motors," Journal of Power Electronics, vol. 13, no. 3, p. 369, 2013.

[8] I. K. E. Cam, "Load Frequency Control In Two Area Power Systems Using Fuzzy Logic Controller," Energy Convers. Manag. vol. 46, no. 2, 2005, pp. 233-243, 2005.

[9] K Manickavasagan, "Fuzzy based Power Flow control of Two Area Power System," International Journal of Electrical and Computer Engineering (IJECE), vol. 2, no. 1, pp. 130-136, 2012.

[10] A. Guediri and D. Ben Attous, "Modeling and Comparison of Ip and Fuzzy-Pi Regulators of Speed Control of Dfim for Supply of Power to the Electrical Network," J Fundam Appl Sci., vol. 10, no. 1, 2018, pp. 181-190.

[11] E. A. H. Abdalla, et al., "Model Behaviorof Cooling Plant Using Subtractive Clustering Anfis At University Buildings," J Fundam Appl Sci., vol. 10, no. 3S, pp. 665-679, 2018.

[12] R. Farhangi, et al., "Load-frequency Control of Interconnected Power System using Emotional Learning-based Intelligent Controller," Power Energy Syst., vol. 36, no. 1, pp.76-83, 2012.

[13] S. Ghoshal, "Optimizations of PID Gains by Particle Swarm Optimizations in Fuzzy Based Automatic Generation Control,” Electr. Power Syst. Res., vol. 2, no. 3, pp. 203-212, 2004.

[14] Sayed Mojtaba Shirvani Boroujeni, et al., "Load Frequency Control in Multi Area Electric Power System Using Genetic Scaled Fuzzy Logic,” International Journal of Physical Sciences, vol. 6, no. 3, pp. 377-385, 2011.

[15] Vikram Kumar Kamboj, et al., "Automatic Generation Control for Interconnected Hydro-thermal System with the help of Conventional Controllers," International Journal of Electrical and Computer Engineering (IJECE), vol. 2, no. 4, pp. 547-552, 2012.

[16] R. Farhangi, et al., "Load-frequency Control of Interconnected Power System using Emotional Learning-based Intelligent Controller," Power Energy Syst., vol. 36, no. 1, pp. 76-83, 2012.

[17] A.M. Abdel Ghany, "Design of Static Output Feedback PID Controller via ILMI Method for APower System Stabilizer," 12th Middle East Power Systems Conference, 2008, pp. 593-599.

[18] Hoseinpoor, et al., "Wind Turbines Controll by Pso Algorithm," J Fundam Appl Sci., vol. 8, no. 2S, pp. 3638-3646, 2016.

[19] A. J. H. Shayeghi, H.A. Shayanfar, "Load Frequency Control Strategies: A State-of-the-Art Survey for the Researcher," Energy Convers. Manag. Sci., vol. 50, no. 2, pp. 344-353, 2009.

[20] Aqeel S. Jaber, et al., "A new Parameters Identification of single area Power System based LFC using Segmentation Particle Swarm Optimization (SePSO) Algorithm," Power and Energy Engineering Conference (APPEEC) IEE Asia-Pacific, 2013, pp.1-6.

[21] Mouellef Sihem, et al., "Optimal Design of Switched Reluctance Motor using PSO Based FEM-EMC Modeling," International Journal of Electrical and Computer Engineering (IJECE), vol. 5, no. 5, 2015, pp. 427-432, 2015.

[22] S. P. Mangaiyarkarasi, et al., "Optimal Location and Sizing of Multiple Static VAr Compensators for Voltage Risk Assessment Using Hybrid PSO-GSA Algorithm," King Fahd University of Petroleum \& Minerals Journal, 2018. 


\section{BIOGRAPHY OF AUTHOR}

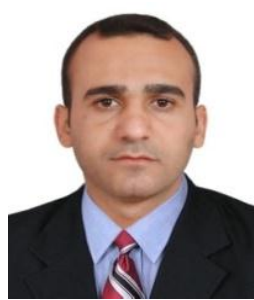

Balasim M.Hussein. He get a BSc in Electrical Power and Machine Engineering from Diyala University (Iraq) in 2004 and a Master's Degree in Electrical Power and Machine Engineering from the Technical University (Iraq) in 2008. He got PhD in 2015 from the Russian south State University (Russia). Currently he is working as a lecturer in the Department of Power Engineering at the Faculty of Engineering, University of Diyala. He has several research papers published in the following journals: science direct, electromechanical journal and modern problems in science journal. 